\title{
Graft Polymerization of Methyl Methacrylate onto Wool Initiated by Hydrogen Peroxide-Sodium Thiosulphate Redox System
}

\author{
Saleh Abdel-Fattah \\ National Research Centre, Textile Research Laboratory \\ Dokki, Cairo, Egypt. \\ Istvan GeCZY \\ Textile Research Institute, Budapest, Hungary.
}

(Received April 5, 1974)

\begin{abstract}
The application of the hydrogen peroxide-sodium thiosulphate redox system to induce graft polymerization of methyl methacrylate onto wool fibers was investigated under various conditions. The effects of solvents monomer concentration, concentration of initiator, and polymerization time were studied. It is shown that dioxane solvent, which acts as a penetrant, is necessary for graft polymerization.

Modified properties of wool fibers grafted with methyl methacrylate were investigated and several properties have been improved. The mechanism of graft polymerization is believed to take place through free radicals on the keratin backbone.

KEY WORDS Hydrogen Peroxide / Sodium Thiosulphate / Wool / Methyl Methacrylate / Dioxane / Grafting /
\end{abstract}

Great intrest has been shown recently in graft polymerization of vinyl monomers onto wool. Polymerization of many vinyl monomers onto wool were studied by a number of workers; ${ }^{1-9}$ the mechanism of the graft polymerization was proposed and their modified properties are reported. The efficiency of thiosulphate to form a redox initiator system with persulphate is known and numerous studies have been published on graft polymerization of vinyl monomers using a redox system..$^{3-5}$ Hydrogen peroxide as an oxidizing agent would be expected to show an initiation effect similar to persulphate. The influence of thiosulphate on grafting has been investigated in detail.

In the present investigation, the feasibility of graft polymerization of methyl methacrylate onto wool fibers initiated by the hydrogen peroxide-sodium thiosulphate redox system was studied. Changes in the physical and/or chemical characteristics of wool and modified wool towards grafting brought forth by this initiator were also studied.

\section{EXPERIMENTAL}

\section{Materials}

Merino wool fibers were extracted for $12 \mathrm{hr}$ with ethanol and ether in a Soxhlet apparatus, then washed with distilled water and air dried. Commercially available methyl methacrylate was washed with 5-\% sodium hydroxide solution as well as with water, dried over anhydrous sodium sulphate, and distilled under reduced pressure in a stream of nitrogen before use.

Hydrogen peroxide, sodium thiosulphate, dioxane, methanol, $N, N$-dimethylformamide, isopropanol, isobutanol, benzene, and thioglycolic acid were first or special reagent grade and were used without further purification.

\section{Esterification}

Esterified wool was prepared by treating purified wool with anhydrous methanol in the presence of $0.1-N$ hydrochloric acid at $65^{\circ} \mathrm{C}$ for $6 \mathrm{hr}$ using liquor ratio of $50: 1 .^{10}$

\section{Reduction}

Reduction of wool was carried out with $0.2-$ $N$ thioglycolic acid for $24 \mathrm{hr}$ at $30^{\circ} \mathrm{C}$ using a 
liquor ratio of $100: 1 .^{8}$

\section{Deamination}

Deamination of wool was performed using nitrous acid $\left(60-\mathrm{g} / l \mathrm{NaNO}_{2}+35-\mathrm{m} l / l\right.$-concentrated $\mathrm{HCl}) .{ }^{11}$

\section{Treatment of Wool with Sodium Thiosulphate} Solution

Wool fibers were treated with $0.1-N$ sodium thiosulphate solution using a liquor ratio of $50: 1$ at $60^{\circ} \mathrm{C}$ for $30 \mathrm{~min}$; the samples were then washed with distilled water and air dried.

\section{Polymerization Reaction}

Three methods were employed for graft polymerization of methyl methacrylate onto wool fibers. The experimental technique adopted for each method is given below.

Method I: Ten $\mathrm{m} l$ of $0.4-N$ sodium thiosulphate solution was introduced into a $100-\mathrm{m} l$ glass-stoppered Erlenmayer flask. The flask was kept at a specified temperature $\left(70^{\circ} \mathrm{C}\right)$. Three$\mathrm{m} l$ freshly distilled methyl methacrylate, $0.5-\mathrm{g}$ wool, $10-\mathrm{m} l$ dioxane, and $5-\mathrm{m} l$ of $30-\%$ hydrogen peroxide were successively added and the contents were diluted with water to $50 \mathrm{~m} l$. The contents of the flask were shaken well and the reaction was allowed to proceed for different time periods $(15-120 \mathrm{~min})$. On completion the samples were extracted with benzene in a Soxhlet apparatus for $18 \mathrm{hr}$. The extracted samples were dried at $105^{\circ} \mathrm{C}$ until constant weight was reached.

Method II: Five $\mathrm{m} l$ of $30-\%$ hydrogen peroxide and $3 \mathrm{ml}$ of methyl methacrylate were mixed in a $100-\mathrm{m} l$ glass-stoppered Erlenmayer flask. To the mixture, $0.5 \mathrm{~g}$ of wool pretreated with sodium thiosulphate was added and diluted with water to $50 \mathrm{~m} l$. The grafting reaction was then allowed to proceed for different time periods $(15-120 \mathrm{~min})$ at a specified temperature $\left(70^{\circ} \mathrm{C}\right)$. Removal of the homopolymer from the grafted wool was performed as described in method $\mathrm{I}$.

Method III: Ten $\mathrm{m} l$ of $0.4-N$ sodium thiosulphate solution, $3 \mathrm{ml}$ of methyl methacrylate, $10-\mathrm{m} l$ dioxane were poured into a $100-\mathrm{m} l$ glassstoppered Erlenmayer flask, together with $0.5-\mathrm{g}$ wool, pretreated with $5-\mathrm{m} l$ of $30-\%$ hydrogen peroxide for $30 \mathrm{~min}$ at $25^{\circ} \mathrm{C}$. The contents were diluted with water to $50 \mathrm{ml}$. The grafting reaction and removal of homopolymer were carried out as described before.

The percentage of grafting was calculated as follows:

$$
\text { Graft }(\%)=\frac{\text { Dry weight of grafted wool }- \text { Dry weight of original wool }}{\text { Dry weight of original wool }} \times 100
$$

The homopolymer formed during grafting was estimated gravimetrically and the percent conversion of monomer to homopolymer was calculated as follows:

\section{Homopolymer (\%)}

$$
=\frac{\text { Dry weight of homopolymer }}{\text { Weight of monomer used }} \times 100
$$

\section{Alkali Solubility}

The alkali solubility of grafted wool was performed in aqueous sodium hydroxide solution $0.1 \mathrm{~N}$ ) at $65^{\circ} \mathrm{C}$ for 1 hour using a liquor ratio of $100: 1 .^{12}$

\section{Urea-Bisulphite Solubility (U-B)}

The solubility of wool in urea-bisulphite reagent was determined according to the method of Dusenbury. ${ }^{12}$

\section{RESULTS AND DISCUSSION}

In a preliminary study of the grafting initiated by the hydrogen peroxide-sodium thiosulphate redox system, three different methods were applied to find the optimum conditions for grafting.

\section{Methods of Graft Polymerization}

In Table I are shown the results of polymerization of methyl methacrylate in the presence of wool fibers using the redox initiation of hydrogen peroxide-sodium thiosulphate in aqueous media. In method $I$, all the components are present together, whereas the results of methods II and III were obtained under conditions different from this. In method II, the thiosulphate as a reducing agent is attached to the wool fibers by ion-exchange and the oxidizing agent (hydrogen peroxide) is subsequently 


\section{S. Abdel-Fattah and I. Geczy}

Table I. Graft polymerization of methyl methacrylate onto wool initiated by hydrogen peroxide-sodium thiosulphate redox system using three different methods at $70^{\circ} \mathrm{C}^{\mathrm{a}}$

\begin{tabular}{|c|c|c|c|c|c|c|c|}
\hline \multirow{2}{*}{$\begin{array}{l}\text { Reaction time, } \\
\min \end{array}$} & \multirow[b]{2}{*}{ Methods } & \multicolumn{3}{|c|}{ Graft yield, $\%$} & \multicolumn{3}{|c|}{ Homopolymer, \% } \\
\hline & & $\mathrm{I}$ & II & $\overline{\mathrm{III}}$ & $\mathrm{I}$ & II & III \\
\hline 15 & & 20.4 & 9.14 & 12.87 & 7.65 & 19.38 & 14.24 \\
\hline 30 & & 122.8 & 33.98 & 45.76 & 9.12 & 22.54 & 20.28 \\
\hline 45 & & 178.0 & 42.16 & 52.76 & $11.20^{\circ}$ & 25.78 & 25.70 \\
\hline 60 & & 247.2 & 57.96 & 57.89 & 14.38 & 30.12 & 28.72 \\
\hline 50 & & 298.2 & 56.80 & 65.87 & 19.72 & 32.00 & 31.65 \\
\hline 120 & & 299.4 & 66.18 & 82.16 & 21.54 & 32.65 & 34.24 \\
\hline
\end{tabular}

a Methyl methacrylate, 6\%; hydrogen peroxide, 3\%; sodium thiosulphate, $0.08 \mathrm{~N}$; dioxane, 20\%; liquor ratio of $100: 1$.

applied with the monomer. In method III, the oxidant (hydrogen peroxide) is applied to the fibers for $30 \mathrm{~min}$ at $25^{\circ} \mathrm{C}$ and then the reducing agent (thiosulphate) is added to the monomer.

The data of Table I, indicate that the graft yield and homopolymer formation increase by increasing the reaction time at first, but later the ratio decreases. The graft yields obtained with method I are significantly higher than those of methods II and III. This could be interpreted in terms of the following possibilities:

The generated free radical would be intimately in contact with the wool molecules. Grafting would thus be promoted rather than homopolymerization under the conditions of method I, as compared with those used in the other two methods. Hence, unless otherwise stated, method I was employed for studying the variables affecting grafting (such as temperature, type of solvent, monomer and initiator concentration, etc.) to describe the optimum conditions for grafting.

\section{Effect of Solvents on Grafting}

It is important to select the most suitable solvents for the graft polymerization of methyl methacrylate onto wool fibers. The results of various solvents affecting the percent of grafting of methyl methacrylate onto wool are shown in Table II.

It can be seen from the data that grafting took place to a small extent without solvents. This may be due to the ability of the methyl methacrylate molecule to penetrate into the internal regions of the wool. It has been reported that acrylonitrile was the only monomer
Table II. Effect of solvents on the graft polymerization of methyl methacrylate onto wool fibers initiated by hydrogen peroxidesodium thiosulphate redox system ${ }^{2}$

\begin{tabular}{lc}
\hline Type of solvent & Grafting, $\%$ \\
\hline Nil & 12.75 \\
$N, N$-dimethylformamide & 25.62 \\
Carbon tetrachloride & 52.14 \\
Benzene & 21.20 \\
2-propanol & 122.62 \\
Isobutanol & 109.18 \\
Methanol & 35.76 \\
Ethanol & 48.82 \\
Dioxane & 334.66 \\
\hline
\end{tabular}

a Methyl methacrylate, 6\%; hydrogen peroxide, $3 \%$; sodium thiosulphate, $0.08 \mathrm{~N}$, solvent percentage, $20 \%$ at $70^{\circ} \mathrm{C}$ for $2 \mathrm{hr}$.

to penetrate into the internal part of the dehydrated wool in the absence of the solvent. ${ }^{13}$

In the present study, among several solvents applied, only dioxane proved to be effective for grafting. The swelling of the inner structure of wool facilitated the diffusion of methyl methacrylate monomer, the initiation and the propagation into the wool.

On the other hand, swelling solvents such as $N, N$-dimethylformamide and ethanol proved to be ineffective. ${ }^{14,15}$ The effect of dioxane concentration on the percentage of graft yield has been further studied, maintaining the temperature and time of polymerization as constants $\left(70^{\circ} \mathrm{C}, 2 \mathrm{hr}\right)$.

Results obtained are illustrated in Figure 1. The data indicate that the percent of grafting 


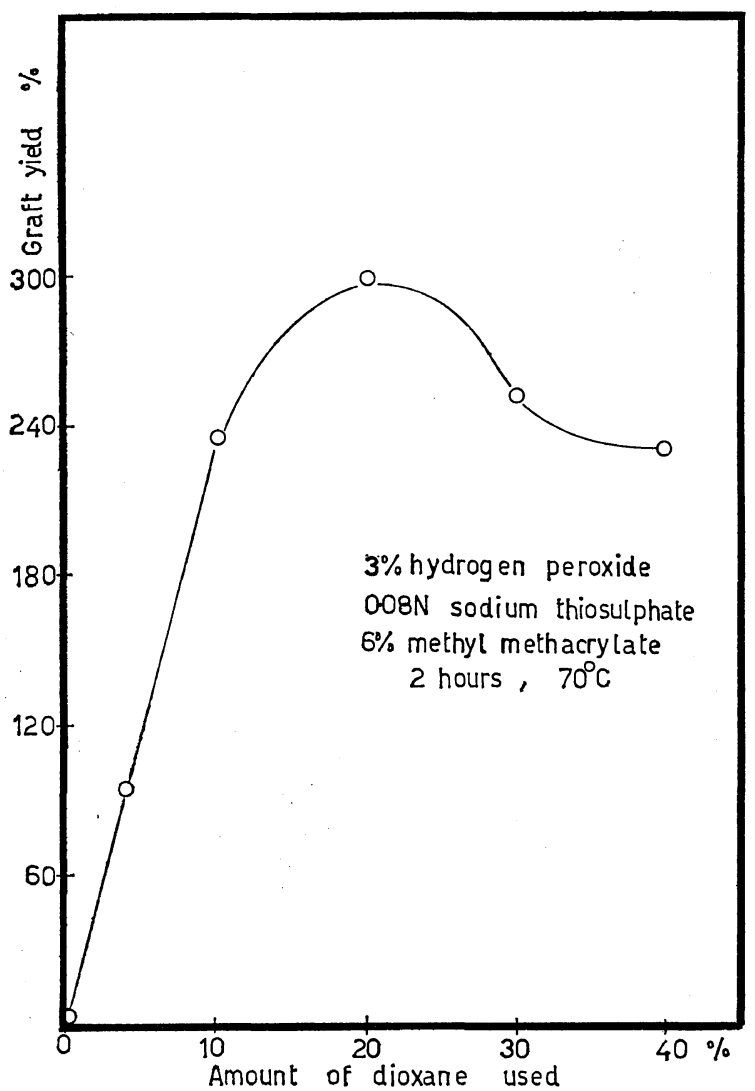

Figure 1. Effect of the amount of dioxane on the graft yield percentage.

increased with increasing the amount of dioxane up to $20 \%$ and then decreased, showing that a rather small quantity of dioxane solvent proved satisfactory to initiate grafting. Hence, 20-\% dioxane as solvent was used for all the experiments unless otherwise stated. The effect of solvent on the percent of graft yield can be explained according to Henrici-Olive. ${ }^{16,17}$ The propagation species can form a charge-transfer complex of each monomer and solvent molecules, but only the complex with monomer leads to propagation.

\section{Effect of Initiator Concentration on Grafting}

The effect of the quantity of hydrogen peroxide on grafting under the experimental conditions (at $70^{\circ} \mathrm{C}$, methyl methacrylate $6 \%$, dioxane 20\%) is shown in Figure 2. All the curves demonstrate that maximum grafting can be obtanined when the hydrogen peroxide con-

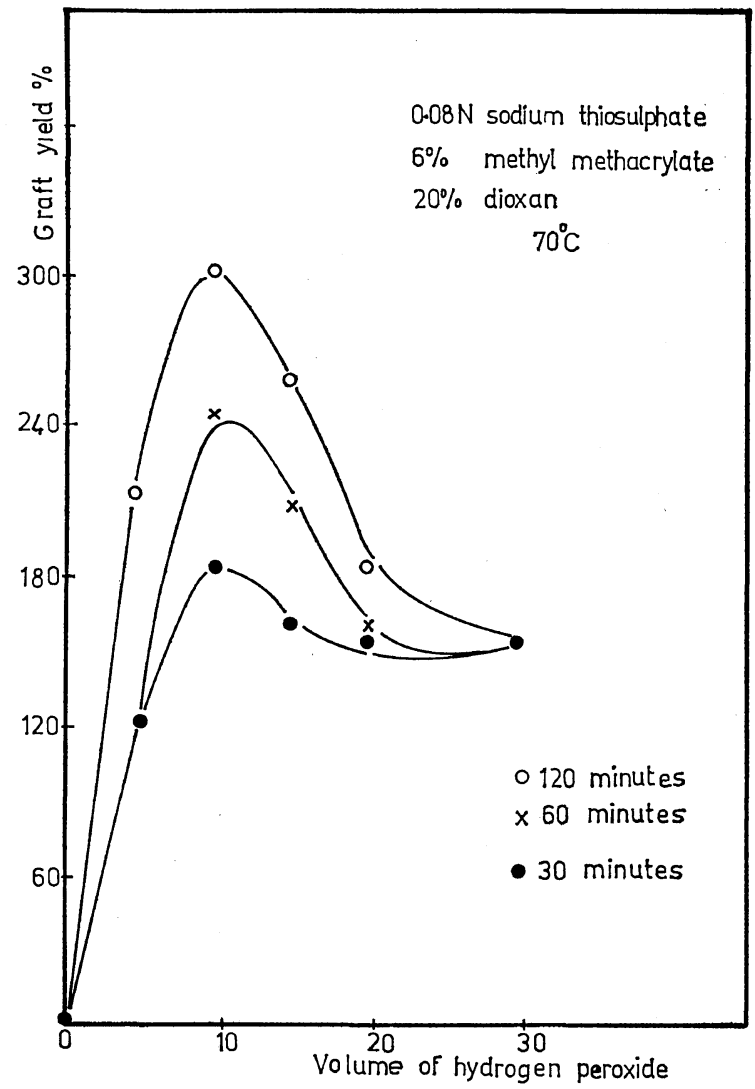

Figure 2. Effect of hydrogen peroxide concentration on the graft yield percentage.

centration is about 3\%; the grafting decreased at higher concentrations.

The effect of sodium thiosulphate concentration on grafting is shown in Figure 3. It can be seen that with sodium thiosulphate concentration increased up to $0.08 \mathrm{~N}$, the percentage of graft yield increases significantly. It should be noticed, however, that the graft yield increased at the initial stage of polymerization reaction but reached a constant level after prolonging the time of grafting.

Effect of the Amount of Monomer on Grafting

The effect of the amount of monomer on the grafting was evaluated in a series of polymerizations in which four concentrations of monomer were used. The results, as shown in Figure 4, show that increasing the monomer percentage from $1 \%$ to $6 \%$ resulted in a significant increase of the graft yield. Hence, the higher rates of 


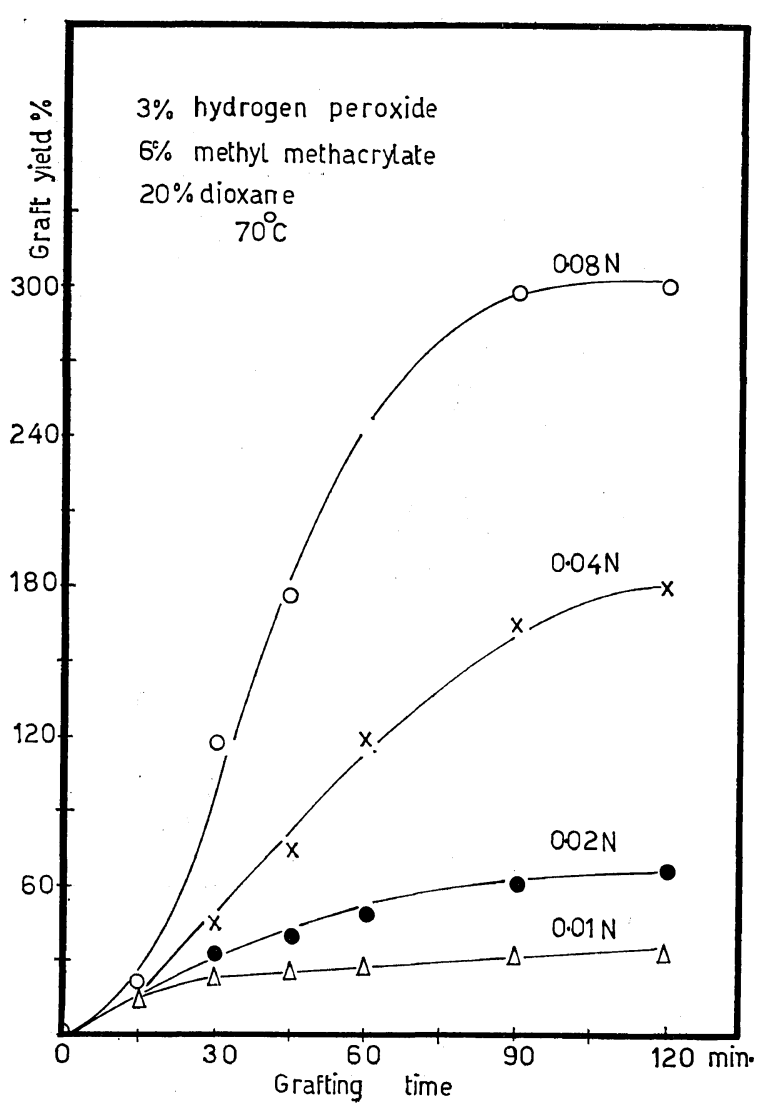

Figure 3. Effect of sodium thiosulphate concentration on the graft yield percentage.

grafting observed by using increased amounts could be attributed to several factors.

\section{Effect of Temperature on Grafting}

Increasing of the polymerization temperature leads to a significant acceleration in the rate of grafting. This can be seen from Figure 5 .

Figures 2-5 show the relation between the polymerization time and the percent of grafting. From the figures, it can be seen that the rate of grafting increases initially, then reaches a steady state.

\section{Grafting of Methyl Methacrylate onto Modified Wool}

The active sites in wool, as for instance the hydroxyl, sulphydryl, amino and imino groups, are capable of forming a redox system with hydrogen peroxide. The results of this investigation with reduced, esterified wool as well as deaminated wool are shown in Table III. It is

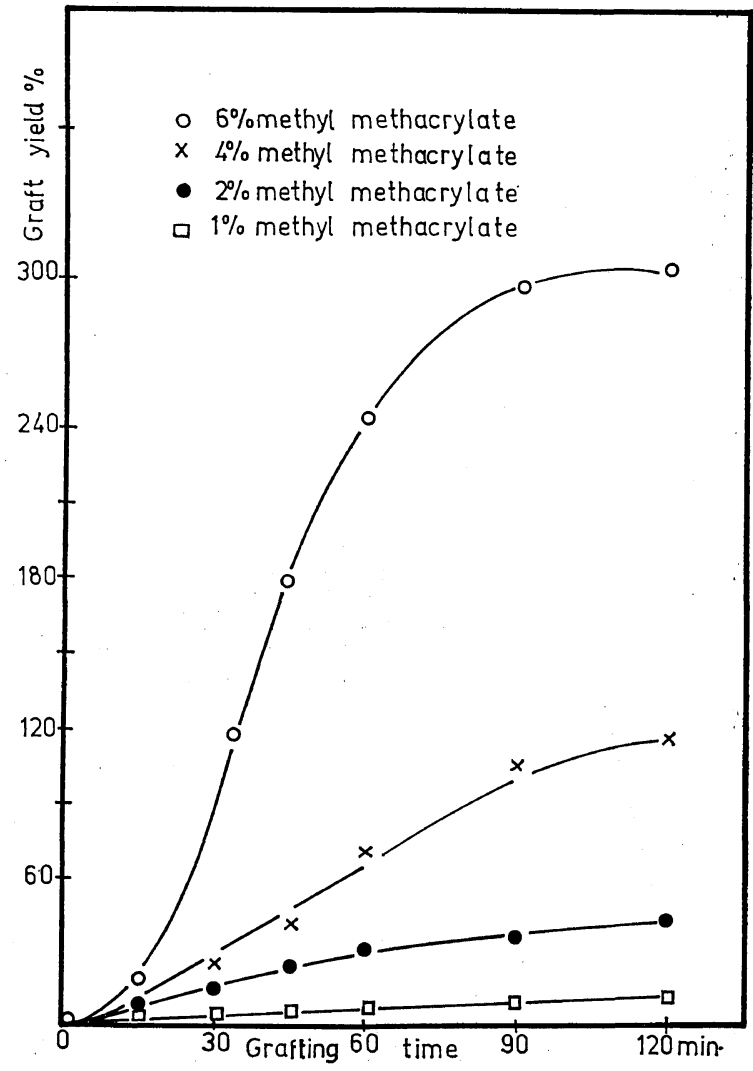

Figure 4. Effect of the amount of methyl methacrylate on the graft yield percentage.

seen that the graft yield of unmodified wool is significantly higher than that of reduced and esterified or deaminated wool at the later stages.

The graft yield values of the esterified wool are substantially lower than those of the unmodified case. This can be attributed to the presence of methyl groups in the esterified wool molecules.

Another interesting feature is that deaminated wool shows graft yield values which are significantly lower than of the unmodified case. This indicates the importance of the amino groups, which are the main sites for initiating the grafting of wool. ${ }^{7-9}$

The more increase in graft percentage of reduced wool than the other modified wool may be explained on the basis that the reduction of cystine-disulphide bond of wool with thioglycolic acid increases the number of thiol groups (- $\mathrm{SH})$ which act as active centres for grafting. 
Moreover, the initiation of grafting might involve not only abstraction of the hydrogen atom of the cysteine - $\mathrm{SH}$, but also the tyrosine $-\mathrm{OH}$ groups on the polypeptide chains. ${ }^{18}$ However, the graft yield values of reduced wool are

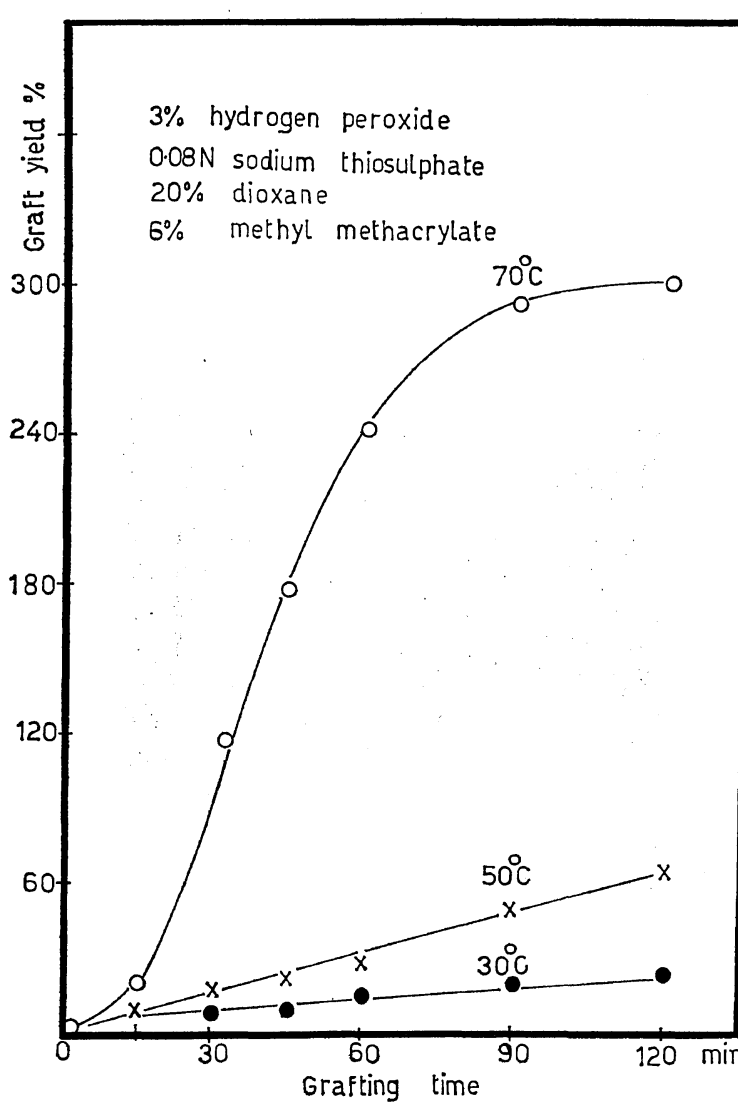

Figure 5. Effect of temperature on the graft yield percentage.

lower to some extent than the unmodified case. This can be attributed to the concrete action of the redox reaction between hydrogen peroxide. thiosulphate, and the amount of the thiol groups over the range of the grafting reaction.

Physico-Chemical Properties of Grafted Wool Fibers

The physico-chemical properties of grafted wool are shown in Table IV. The alkali solubility of grafted wool and wool treated with redox system (the same conditions of grafting except that methyl methacrylate was absent) are shown in the table; its value is expressed as the ratio of the ratio of the soluble wool fraction per part of the protein of grafted wool. It can be seen from the table that the solubility of wool in urea-bisulphate reagent (U-B) and

Table III. Graft polymerization of methyl methacrylate onto wool and modified wool initiated by hydrogen peroxide-sodium thiosulphate redox system ${ }^{\mathrm{a}}$

\begin{tabular}{crrrr}
\hline $\begin{array}{c}\text { Grafting } \\
\text { time, } \\
\text { min }\end{array}$ & \multicolumn{4}{c}{ Graft yield, \% } \\
\cline { 2 - 5 } modified & Reduced & \multicolumn{1}{c}{$\begin{array}{c}\text { Esteri- } \\
\text { fied }\end{array}$} & $\begin{array}{c}\text { De- } \\
\text { aminated }\end{array}$ \\
\hline 15 & 20.40 & 75.40 & 40.63 & 13.21 \\
30 & 122.82 & 167.40 & 150.24 & 17.81 \\
45 & 178.13 & 227.18 & 170.67 & 20.53 \\
60 & 247.30 & 242.00 & 188.62 & 24.24 \\
90 & 298.20 & 247.00 & 194.40 & 27.62 \\
120 & 299.50 & 250.00 & 211.60 & 30.86 \\
\hline a Methyl methacrylate, 6\%; hydrogen & peroxide, \\
3\%; sodium thiosulphate, 0.08 $N$; dioxane, 20\%; \\
liquor ratio, 100: 1 at $70^{\circ} \mathrm{C}$.
\end{tabular}

Table IV. Properties of grafted wool fibers ${ }^{a}$

\begin{tabular}{|c|c|c|c|c|c|c|}
\hline \multirow{2}{*}{$\underset{\min }{\text { Grafting time, }}$} & \multirow{2}{*}{ Grafting, $\%$} & \multicolumn{2}{|c|}{ Alkali solubility, $\%$} & \multirow{2}{*}{$\frac{\text { U-B solubility, } \%}{\text { Grafted }}$} & \multirow{2}{*}{$\begin{array}{c}\text { Moisture } \\
\text { absorbed }^{\mathbf{b}}\end{array}$} & \multirow{2}{*}{$\underset{\text { shrinkage }}{\text { Area }}$} \\
\hline & & Grafted & Treated & & & \\
\hline 0 & 0 & \multicolumn{2}{|c|}{16.60} & 46.21 & 13.71 & 29.42 \\
\hline 15 & 20.40 & 10.69 & 28.00 & 20.32 & 10.32 & 10.82 \\
\hline 30 & 34.98 & 7.82 & 30.00 & 13.78 & 8.24 & 7.36 \\
\hline 60 & 57.96 & 3.46 & 32.00 & 10.48 & 6.83 & 0.00 \\
\hline 120 & 299.40 & 0.52 & 36.00 & 6.42 & 3.21 & 0.00 \\
\hline
\end{tabular}

a Methyl methacrylate, $6 \%$; hydrogen peroxide, $3 \%$; sodium thiosulphate, $0.08 \mathrm{~N}$; dioxane, $20 \%$, liquor ratio, $1: 100$ and at $70^{\circ} \mathrm{C}$.

b At $60-\%$ RH for one week.

c Laundered in $2-\%$ soap solution at $40^{\circ} \mathrm{C}$ for $0.5 \mathrm{hr}$ 


\section{S. Abdel-Fattah and I. Geczy}

in alkali decreased significantly after grafting, whereas treatment of wool with the redox system only increased its solubility. The decrease in solubility of grafted wool may be caused by:

1) Formation of inter or intramolecular crosslinks between polypeptide chains via termination of two radicals and/or growing chain radicals. ${ }^{8,19}$

2) The presence of the polymer grafted onto the wool may produce a barrier which impedes the alkali from penetrating into the wool interior.

The evidence for the formation of crosslinks onto grafted wool may be reflected from its decreased solubility in urea-bisulphite reagent (see Table IV). It had been pointed out that the introduction of relatively few stable crosslinks (lanthionine) into native wool could render it completely insoluble in the urea-bisulphite reagent. ${ }^{20}$ It can be noticed also from the table that moisture absorption as well as area shrinkage decreased significantly upon the increase of grafting.

\section{REFERENCES}

1. M. Lipson and J. B. Speakman, J. Soc. Dy. Col., 65, 390 (1949).

2. N. K. Boardman and M. Lipson, ibid., 69, 335 (1953).

3. C. H. Sorum and J. O. Edwards, J. Amer.
Chem. Soc., 74, 1204 (1952).

4. P. Chosh, S. C. Chadha, and S. R. Palit, J. Polym. Sci. Part A-2, 2, 4441 (1964).

5. J. A. Church, ibid., Part A-1, 5, 3183 (1967).

6. O. Yashitaka and K. Hitchi, J. Appl. Polym. Sci., 14(3), 817 (1970).

7. A. Kantouch, A. Hebeish and A. Bendak, Eur. Polym. J., 7, 159 (1971).

8. A. Kantouch, S. H. Abdel-Fattah, and A. Hebeish, Polym. J., 6, 675 (1972).

9. S. H. Abdel-Fattah, A. Kantouch, and A. Hebeish, Egyptian J. Chem., 17, (4), (1974) in press.

10. P. Alexander, D. Carter, and O. E. Ford, Biochem. J., 48, 629 (1951).

11. I. Rusznak and A. Pataki, Magy. Kem. Foly., 60, 282 (1954).

12. J. H. Dusenbury, J. Text. Inst., 51, T758 (1960).

13. M. Burke, P. Kenny, and C. H. Nicholls, ibid., 53, T370 (1962).

14. R. T. Hayes, J. Polym. Sci., 11, 531 (1953).

15. I. Sakurada, T. Okada, and S. Tarikai, Chem. High Polymers (Japan), 18, 550 (1961).

16. G. Henrici-Olive and S. Olive, Z. Phys. Chem., 47, 286 (1965); 48, 35, 51 (1966).

17. G. Henrici-Olive and S. Olive, Makromol. Chem., 68, 219 (1963); 96, 221 (1966).

18. M. Negishi and K. Arai, J. Appl. Polym. Sci., 9, 3465 (1965).

19. K. Arai, S. Komine, and M. Negishi, J. Polym. Sci., Part A-1, 8, 917 (1970).

20. K. Lees, R. V. Peryman and F. F. Elsworth, J. Text. Inst., 51, T717 (1960). 